\title{
Raising Course Efficacy to Improve Management Student Learning: Three Field Experiments
}

\author{
Shoshi Chen \\ Tel Aviv University
}

Oranit Davidson Begerano

Peres Academic Center

\author{
Mina Westman \\ Tel Aviv University
}

Dov Eden

Tel Aviv University

\begin{abstract}
"Means efficacy" complements self-efficacy. It refers to one's belief in the usefulness of external resources or tools that may be useful for performance. Research has confirmed the hypothesis that enhancing means efficacy boosts performance. Course efficacy is students' belief in the usefulness of a course. Two pilot studies and three field experiments tested the means efficacy-performance hypothesis casting university courses as the means. The manipulation check validated the experimental treatment in only one pilot and there was no evidence that the treatment contributed to performance. Explanations of these results and ideas for future research are suggested.
\end{abstract}

Keywords: means efficacy, motivation, performance, field experimentation

\section{INTRODUCTION}

Self-efficacy is a belief about self. It refers to one's beliefs in one's capabilities to organize and execute the courses of action required to manage prospective situations (Bandura, 1997). Ample research supports the hypothesis that boosting self-efficacy motivates intensification of effort, culminating in enhanced performance. (e.g., Eden \& Sulimani, 2002; Gist \& Mitchell, 1992; Maddux \& Kleiman, 2018; Stajkovic \& Luthans, 1998). Whereas self-efficacy is belief in one's own internal resources, "means efficacy" is a complementary construct that refers to one's belief in the usefulness of external resources (Eden, 2001). Total subjective efficacy is the sum of internal efficacy and external efficacy (Eden, 2013). External resources include the available tools - means - for achieving successful task performance. It may be a pair of pliers, a computer, a fork lift, a weapon, a lantern, an IT system, or any other tool or means that an individual may — or may not-believe to be useful for task performance. External resources may also include training and supervisory leadership provided by the organization, or a group of coworkers or team, 
all of which an individual may believe are - or are not - instrumental means for achieving successful performance. In sports external efficacy includes home-court advantage and, sometimes, the weather. The means efficacy construct has even been extended to a competitor's opening position in a board game. Informing a random half of players that their opening position gave them a competitive advantage over their adversary - though it in fact made no real difference at all-increased their likelihood of winning (Stirin, Ganzach, Pazy, \& Eden, 2011). Most research on external efficacy has been focused on work tools-means for performing a job. The present experiments extended the means-efficacy construct to include university courses - mostly organizational behavior courses, as means for achieving prized career outcomes.

Self-efficacy and means efficacy both are beliefs. Self-efficacy is not one's ability; rather, it is what one believes about one's ability. Similarly, means efficacy is not the tool's usefulness; rather, it is what one believes about the tool's usefulness. That subjectivity is what makes both self-efficacy and means efficacy malleable and manipulable for the experimenter. Self-efficacy is positively associated with motivated effort, culminating in successful performance (Bandura (1997). In parallel, it is hypothesized that when means efficacy is enhanced it motivates effort, culminating in enhanced performance (Eden, 2001).

\section{PREVIOUS RESEARCH}

Several lines of theory and research have considered and tested the role of means efficacy in affecting performance (e.g., Agars, 2010; Jones, Agars, \& Kottke, 2010; Rice \& Kottke, 2007). By enhancing means efficacy, experimenters have effected improvements in the productive utilization of computers among social service workers and among students (Eden, Ganzach, Flumin-Granat, \& Zigman, 2010); reduced job stress and strain among employees coping with new information technology (IT; Chen, Westman, \& Eden 2009); and strengthened military trainees' mastery of their weapons and their motivation to use them (Eden \& Sulimani, 2002). Zhou, Wang, Chang, Liu, Zhan, \& Shi (2017) defined "commuting means efficacy" as workers' belief that the means of transportation to work can get them there safely and punctually and found that it buffers the effects of commuter stress on self-regulation at work. Yaakobi and Weisberg (2018) showed that means efficacy explained variance in performance beyond that explained by self-efficacy and collective efficacy among high-tech employees. Leadership scholars have woven means efficacy into their theories of effective leadership (e.g., Hannah, Avolio, \& May, 2011; Hannah, Avolio, \& Walumbwa, 2010; Walumbwa, Avolio, \& Zhu, 2008).

Causality is evident in the confirmatory field-experimental demonstrations of the effects of augmenting means efficacy. Productive outcomes of means-efficacy enhancement have been achieved with no additional investment of time or money. Reaping the benefits of boosting means efficacy requires only awareness of its role in motivating effort and mindful leader actions to enhance it. Moreover, reaping practical benefit from means efficacy theory does not require adding resources; rather, it requires strengthening beliefs in the resources that are in hand. Indeed, self-efficacy and means efficacy are themselves resources that should be husbanded and enriched.

Most of the means-efficacy research cited above was experimental. An exception is Rotstein and Erez's (2010) field study among new immigrants in vocational retraining to facilitate employment in their new country. Rotstein and Erez measured means efficacy, core self-evaluations (CSE), and satisfaction with the program. They found that course efficacy-participants' belief that the course would help them gain employment-was significantly positively related to improved post-training employment status, but that CSE was not. Furthermore, means efficacy and CSE interacted such that the positive relationship between course efficacy and subsequent employment status was strong among trainees with high CSE, moderate among those with intermediate CSE, and nil among those of low CSE. Course efficacy was also related to satisfaction with the program. Rotstein and Erez's (2010) findings support the means efficacy hypothesis. They show that a course can be conceived of as a means, and belief in the usefulness of the course for obtaining a prized outcome (i.e., posttraining employment) can be conceived of as variant of means efficacy that is relevant to training. However, the course involved vocational retraining, not university education. Furthermore, correlational research can confirm the relationship between means efficacy and any dependent 
variable, but it cannot confirm causality. Testing the effects of raising means efficacy to affect any outcome requires experimentation.

The present research tested the notion that raising the means efficacy of a university management course can produce valued learning outcomes as have previously tested means (computer systems, course websites, weapons, IT). If confirmed, it would put an additional tool into the hands of educators, training professionals, and training directors; beyond doing all they can to boost student and trainee self-efficacy, they could act also to boost their means efficacy: get students to believe in the usefulness of their courses and get trainees to believe in the usefulness of their training. The cost of enhancing means efficacy is nil but the return can be great.

\section{THE PRESENT EXPERIMENTS}

The main aim of the present experiments was to test the effects of enhancing means efficacy in a university context. Courses can be viewed instrumentally, as means, and "course efficacy" as a special instance of means efficacy. Course efficacy is students' belief in the usefulness of their course as a means for accomplishing goals and obtaining outcomes. We embarked on a program of experimentation to test whether enhancing students' course efficacy would culminate in greater course achievement.

Because means efficacy is hypothesized to operate in a manner similar to the way self-efficacy operates, we assume that both constructs can be enhanced by similar mechanisms. According to Bandura (1997), efficacy beliefs can be developed from four major sources: personal mastery experience, vicarious experience, verbal persuasion, and physiological and emotional states. We based our experimental treatments on two of these sources that we deemed to be amenable to manipulation among management students: verbal persuasion and vicarious experience.

Previous self-efficacy and means-efficacy experiments had employed verbal persuasion. It is readily manipulable. It entails simply telling individuals consistently in myriad ways that they have the capacity to succeed (self-efficacy) and that the tools at their disposal are effective (means efficacy). Going beyond past experimentation, we sought to strengthen the treatment by employing also vicarious experience. Vicarious experience exposes participants to successful models (Bandura, 1997). Seeing someone similar to oneself succeed at a task strengthens one's self-efficacy for succeeding at that task; "If he or she can do it, so can I!" We extended this to means efficacy. Knowing that a particular means in the hands of a similar other led to success should strengthen one's belief that in one's own hands that means will bring similar success. "This means (ax, microscope, computer, exercise bike, course, etc.) worked well for him or her-it will work well for me, too." To achieve this, we employed recent graduates from the same course to administer verbal persuasion. Hearing praises of the course's usefulness from a credible model similar to oneself, a participant's course efficacy should be enhanced by the model's verbal persuasion and by his or her attribution of successful attainment to the course. Except in one experiment, we ruled out the easier alternative of administering the treatment ourselves because of the numerous ways in which we differ from the students. Such differences may make the treatment less credible than hearing it from a former student who is similar to the participants in age, status, and education. This novel way to deliver the experimental treatment promised to enhance our knowledge and understanding of means efficacy and the ways to increase it.

The prime dependent variable of interest in efficacy research is performance. The main aim was to test the impact of raising course efficacy on subsequent course achievement. Also assessed in some experiments were ancillary outcomes such as course satisfaction and attendance. The main hypothesis tested was that raising means efficacy enhances performance. Based on this hypothesis, we predicted that experimental students who were exposed to a course-efficacy-boosting treatment would outperform students in the control condition. Performance was to be measured by exam scores or final course grades, when available.

Unlike Rotstein and Erez' (2010) field study, the independent variable in these experiments was not means efficacy; it was raising means efficacy. Testing the hypothesis requires a treatment that enhances means efficacy. Therefore, experimentation was indispensable. As effects of boosting self-efficacy on performance is tested by treatments that raise participants' beliefs in their knowledge, skills, and abilities, 
so the effects of boosting means efficacy on performance must be tested using experimental treatments that raise participants' beliefs in the usefulness of some means. Otherwise, one could counter argue that performance affected efficacy beliefs.

\section{PILOT STUDIES}

Two pilot experiments tested the experimental treatment and the measures. The first pilot study (Names withheld to protect anonymity, 2011) was a randomized, pretest-posttest experiment among first-year MBA students taking a required Introduction to Organizational Behavior (OB) course. We randomly assigned 30 students to the experimental condition and 32 to the control condition. Next, we employed verbal persuasion and vicarious experience to enhance course efficacy among the experimental students. An EMBA graduate, who was serving as a company $\mathrm{CEO}$, administered the treatment. He told the students about his own managerial experience since the course and how he was using the knowledge he had gained in the course. Control students heard a lecture about the history of the field of OB. Students in both groups completed measures of course efficacy and of potential outcomes.

The introductory page of the questionnaires in all of the present experiments included a statement informing participants that their participation was voluntary, that anonymity was assured, that no one would see their questionnaires except the research team, and that they were free to refuse to participate with no penalty. This information was also conveyed orally at every questionnaire administration.

Because means efficacy is task-specific, each task investigated requires a unique measure of means efficacy. These measures typically have about a dozen items and are highly reliable (e.g., Chen et al., 2009: $\alpha=.78, .90$, and .90 on successive occasions; Eden et al., 2010: $\alpha=.95$ and .99 on successive occasions; Stirin et al., 2011: $\alpha=.86$ ). We based a 17-item measure of course efficacy on its conceptual definition and on measures used in past means efficacy research. Students indicated on a 5-point agreement/disagreement scale with such statements as, "The OB course is useful for me" and "The OB course will help me to be a better manager." Coefficient $\alpha$ was .93 on the first occasion and .90 on both the second and third occasions. Grades gauged performance. The results were of slight magnitude and fell short of statistical significance. The groups did not differ in means efficacy. We concluded that the measures were reliable and perhaps valid but that we needed to improve the experimental treatment. Perhaps the former EMBA student serving as a CEO was too dissimilar from current students in status to influence them as a model.

We decided to replicate using models that were more similar to the students. We based this decision on Festinger's (1954) theory of social comparison that others who are similar will be preferred for comparison because information about similar others is most informative for self-evaluation (see also Tesser, Millar, \& Moore, 1988). Levy, Freitas, and Salovey (2002) maintained that perceiving similarity between oneself and others can lead one to take the others' perspectives.

The second pilot study involved 125 students enrolled in an OB course. Grades were inaccessible. We measured satisfaction and attendance. The experimental treatment was the same as that used in the first pilot except that our model was a male novice manager who had taken the same course with the same instructor one semester earlier. Coefficient $\alpha$ for means efficacy was .91 on the first occasion and .92 on the second occasion. The outcome variables were single-item self-reports of course satisfaction and attendance. The experimental and control groups differed significantly in means efficacy after the treatment. This was evidence that the treatment affected course efficacy as intended. This validated the treatment as an effective way to enhance course efficacy.

As predicted, posttest course efficacy was associated with both course satisfaction and attendance. This was the first test of the effects of course efficacy on outcomes. Course efficacy can be enhanced and enhancing it improves course satisfaction and attendance. These confirmatory results validate the courseefficacy treatment and confirm the means efficacy $\rightarrow$ outcomes hypothesis. The results were an encouraging backdrop to follow-on course-efficacy experiments. Unfortunately, the lack of performance data restricted the value of this pilot experiment. 


\section{FIELD EXPERIMENT 1: BOOSTING THE MEANS EFFICACY OF AN INTRODUCTION TO OB COURSE}

Experiment 1 was a true field experiment among MBA students taking Introduction to $\mathrm{OB}$. The experiment was conducted in partial fulfilment of the requirements for a master's degree (Name withheld). It was intended to test the means-efficacy hypothesis by boosting means efficacy among students enrolled in the course. We also measured and statistically controlled general self-efficacy (GSE; Chen, Gully, \& Eden, 2001, 2004), a correlate of means efficacy. GSE predicts performance in many situations (e.g., Chen et al., 2000; Eden \& Aviram, 1993; Gist et al, 1989; Shelton, 2000; Vancouver \& Purl, 2017; Yokoyama, 2019). Measuring GSE enabled us to test also the interaction between GSE and course efficacy in affecting outcomes. This is a test of Brockner's $(1985,1988)$ behavioral plasticity hypothesis according to which individuals with low self-esteem are influenced more than are individuals with high self-esteem by myriad external stimuli, including experimental treatments; their behavior is more "plastic." Persons high in selfesteem are influenced less. Persons low in self-esteem are less self-assured and therefore let outside factors affect them more. For example, they welcome training and take advice willingly. In contrast, those high in self-esteem are self-confident and are reluctant to let outside forces affect them, including experimental treatments. Experimental replications have shown that GSE operates similarly to self-esteem in the plasticity phenomenon (e.g., Eden \& Aviram, 1993; Eden \& Zuk, 1995). Based on the plasticity hypothesis, we predicted that the treatment would influence students low in GSE more than those high in GSE.

\section{Method}

\section{Design and Sample}

We randomized 48 students into the experimental condition and 46 into the control condition. Of these $94,63 \%$ were men, $96 \%$ were working, and $39 \%$ had had experience managing. Four students dropped the course and another two did not take the final examination. Therefore, the means-efficacy hypothesis was tested among the 88 students that were present for the treatment and took the final. For some analyses we had data on all 94 students in the original sample.

\section{Procedure}

At the first class session the instructor described the course in general. To disguise the randomized assignment to conditions, the instructor then informed the students that for some topics and exercises the class would be split into two study groups and that each group would have a different instructor. The pretext, true in itself, was that some things are learned more effectively in smaller groups. Then the students were assigned to their randomly predetermined groups. The students did not know that the group assignments were random. The instructor knew the assignments were random but did not know which was the experimental group and which was the control group. This prevented instructor bias.

The pretest questionnaire was completed at the end of the first class session during which the experimental treatment was rendered. Two months later, after the final exam, the students completed the posttest questionnaire; 84 complied and 65 of them had completed pretest questionnaires. The posttest questionnaire measured only course efficacy to gauge the lasting effect of the experimental treatment.

\section{Treatment}

Each group viewed a short video that portrayed two "managers," one man and one woman, dealing with a managerial dilemma. These managers were models who had taken the same OB course one year previously. They were selected for this role because they were similar to the student participants except that the models had had rich managerial experience. Having experienced students who recently had taken the same course enact the manager roles in the videos maximally operationalized verbal persuasion and vicarious experience due to their demographic similarity to the student participants (age, sex, and, still being students, socioeconomic status) and due to their managerial experience.

After viewing the video, each group was instructed to discuss the dilemma and to suggest solutions that they deemed appropriate. Then each group viewed a different version of a follow-on video. In both versions 
the same models showed the same solution that they had reached. In the control version the models presented and discussed the solution without associating their explanation of how they arrived at the solution to any aspect of the OB course. In the experimental version the models presented the same solution and detailed the $\mathrm{OB}$ research, theories, and approaches that helped them reach their solution. They also declared how much the OB course had contributed to improving their managerial skills. After discussing the videos, both groups returned to the larger classroom to continue that first day's class session.

\section{Measures}

The questionnaire included demographic items and a question asking whether the respondent had managerial experience. We devised, again, a scale of 17 5-point Likert items to measure course efficacy. The items were preceded by the following statement: "MBA studies contribute to success in management. Think about the OB course as a means for developing your managerial career. To what extent do you think each of the following statements is true of the OB course." Sample items: "Prepares students to be successful managers" and "Provides advantages for a career in management." Pretest and posttest $\alpha=.93$ and .92, respectively. GSE was gauged using the NGSE (New General Self-efficacy) scale (Chen, Gully, $\&$ Eden, 2001). The NGSE is a widely-used 8-item measure of trait-like GSE with demonstrated reliability and validity (present $\alpha=.90$ ). Students self-reported their attendance. Performance was gauged using the final examination grades. These were on a 20 -point scale.

\section{Results}

Table 1 shows that the experimental and control groups did not differ on average in any of the major variables measured. The randomization succeeded but the experimental treatment did not. Repeatedmeasures ANOVA detected no main effect of Treatment (F1, $63=1.09$, n.s.) but did detect a significant main effect of Occasion $(\mathrm{F} 1,63=9.26, \mathrm{p}<.01)$ for course efficacy. The Treatment X Occasion interaction was not significant $\left(F_{1,63}=0.002\right.$, n.s. $)$, indicating that the degree of change in both conditions was similar. Inspection of the means in Table 1 reveals that course efficacy waxed appreciably in both groups. The general increase in course efficacy is not what we predicted and does not support our hypothesis. Of course, it is good news for MBA programs that require Introductory OB.

The means efficacy hypothesis was not tested experimentally; because the treatment did not produce the intended effect on means efficacy, it was not manipulated and the hypothesis could not be tested experimentally. Nevertheless, with the data in hand, it was possible to test the hypothesis post hoc. We regressed the exam scores on the demographic variables, on self-efficacy, and on measured course efficacy. Table 2 and Figure 1 present these results. Only course efficacy had a main-effect relationship with grades and it was positive; the greater the student's belief in the course's efficacy, the better he or she performed. This is evidence in support of the course efficacy hypothesis. However, it is not as strong as experimental evidence.

\section{TABLE 1 \\ COMPARISON OF EXPERIMENTAL AND CONTROL GROUPS, MBA ORGANIZATIONAL BEHAVIOR COURSE, EXPERIMENT 1}

\begin{tabular}{|c|c|c|c|c|c|c|c|c|}
\hline \multirow[b]{2}{*}{ Variable } & \multirow[b]{2}{*}{ Occasion } & \multicolumn{3}{|c|}{ Experimental } & \multicolumn{3}{|c|}{ Control } & \multirow[b]{2}{*}{$t$} \\
\hline & & $M$ & $S E$ & $n$ & $M$ & $S E$ & $n$ & \\
\hline Course efficacy & 1 & 3.24 & 0.71 & 48 & 3.31 & 0.54 & 46 & 0.56 \\
\hline Course efficacy & 2 & 3.44 & 0.62 & 33 & 3.58 & 0.62 & 32 & 0.88 \\
\hline Self-efficacy & & 4.17 & 0.53 & 48 & 4.17 & 0.50 & 46 & 0.03 \\
\hline Attendance & & 3.25 & 1.08 & 48 & 3.39 & 0.82 & 46 & 0.70 \\
\hline Grades & & 16.24 & 2.23 & 45 & 16.27 & 1.98 & 43 & 0.07 \\
\hline
\end{tabular}

Note. Sample on Occasion 2 includes only those who had completed the pretest questionnaires. 
TABLE 2

REGRESSION OF EXAM SCORES ON DEMOGRAPHIC PREDICTORS, GSE, AND COURSE EFFICACY EXPERIMENT 1

\begin{tabular}{|c|c|c|c|c|c|c|}
\hline Variable & $B$ & $\beta$ & $S E$ & $t$ & $R^{2}$ & $\Delta R^{2}$ \\
\hline Step 1 & & & & & 0.03 & \\
\hline Age & -0.02 & .04 & 0.07 & 0.35 & & \\
\hline Sex & -0.51 & .13 & 0.55 & -1.05 & & \\
\hline Managerial experience & 0.18 & .04 & 0.47 & 0.38 & & \\
\hline GSE & -0.29 & 1.51 & 0.49 & -0.59 & & \\
\hline Course efficacy & $0.77 *$ & 2.71 & 0.38 & 1.99 & & \\
\hline \multicolumn{7}{|l|}{ Step 2} \\
\hline GSE $x$ course efficacy & $-1.97 * *$ & 3.20 & 0.73 & -2.67 & 0.11 & 0.08 \\
\hline
\end{tabular}

Note. $n=88 .{ }^{*} p<.05 .{ }^{* *} p<.01$.

FIGURE 1

RELATIONSHIP BETWEEN COURSE EFFICACY AND GRADES AMONG PARTICIPANTS OF LOW, MEDIUM, AND HIGH GENERAL SELF-EFFICACY, EXPERIMENT 1

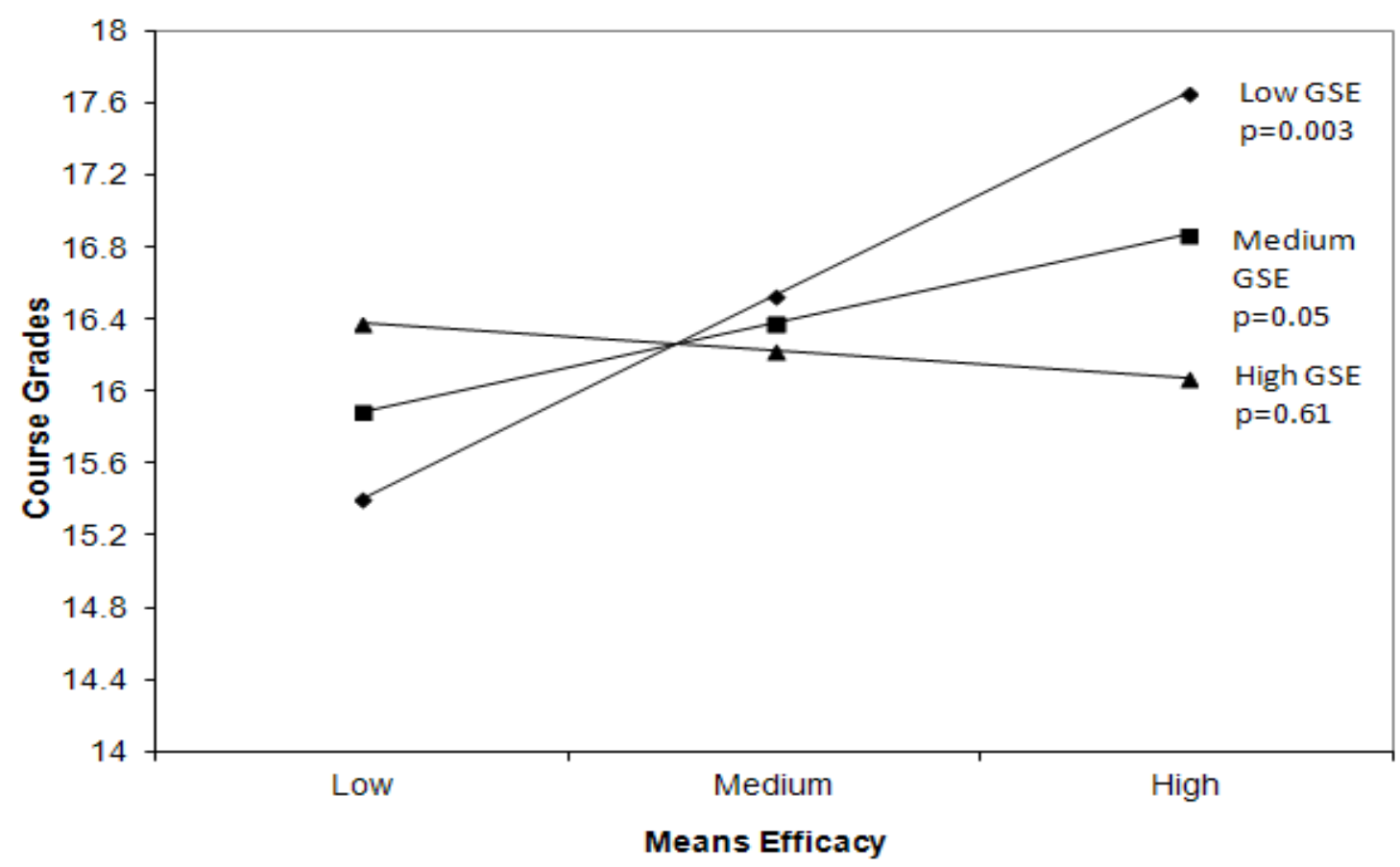

The significant interaction between course efficacy and self-efficacy, depicted in Figure 1, indicates that the relationship between course efficacy and performance varied with levels of GSE; it was strongest among participants with low GSE, moderate among those of middling GSE, and nil among those of high GSE. This replicates previous findings that confirm the behavioral plasticity hypothesis.

\section{Discussion}

The post-hoc results for course efficacy were in the predicted direction. However, they lack the persuasiveness of previous means-efficacy experiments that had produced highly internally valid evidence of a strong causal relationship between means efficacy and performance when the means studied were computer software, course web sites, IT, and weapon systems. Looking back, perhaps the control treatment 
was as effective as the experimental treatment in boosting course efficacy. Perhaps viewing the film and participating in the discussion of the issues in the control group was sufficient to enhance course efficacy no less than the experimental treatment that emphasized the contribution of the organizational behavior course.

Perhaps different kinds of courses are differentially amenable to means-efficacy experimental treatments. After these tests of the course efficacy $\rightarrow$ performance hypothesis in organizational behavior courses, we switched to an entirely different type of course. This was also to achieve constructive or conceptual replication by varying the field setting in which the experiment is conduced (Hendrick, 1990; Lykken, 1968; Rosenthal, 1990). Experiment 2 studied an MBA business game course.

\section{FIELD EXPERIMENT 2-A BUSINESS GAME COURSE}

Many MBA programs require a business-game course (Ben Zvi, 2007; Cruz-Cunha, 2012; Geithner \& Menzel, 2016; Gold \& Wolfe, 2012; Wolfe, 2016). The game is played for a full semester by several competing teams who make a series of business decisions throughout the semester. Each team self-appoints several managerial role incumbents (e.g., finance, marketing, human resources) who must cooperate with each other to compete successfully against the other teams. Each team is responsible for improving shortand long-term performance and to create a competitive advantage in the fiercely competitive arena in which it operates. The students learn from applying the knowledge they have acquired in their management courses. Participants experience the challenges of an interdisciplinary project team as well as project management in complex and rapidly changing situations. Each team member becomes a specialist in his or her function, and a joint effort is required to achieve the common objectives of the company. The game generates many objective, quantitative performance indicators, which are the basis for students' grades and served as the dependent variables in the present experiment.

Students may have varied beliefs regarding how useful the business game is for their future success in management. We conceptualized "business-game efficacy" as a special case of means efficacy in which the business-game is the means. Experiment 2 tested our attempt to produce better learning outcomes among students by boosting their belief in the efficacy of the business game. The hypothesis was, again, that enhancing course efficacy boosts course performance. We predicted that students exposed to an experimental treatment designed to strengthen their belief in the potential contribution of playing the business game to their future management career would outperform students playing the same game in the control group.

\section{Method}

Sample and Design.

This was a true field experiment among $60 \mathrm{MBA}$ students during their last semester at the [name withheld to protect anonymity] University business school who were enrolled in the required business game. All were working while studying and had had managerial experience. Of these, 40 students completed the first questionnaire (65\% participation rate).

\section{Procedure and Experimental Treatment.}

We randomly assigned 31 students to the experimental group and 29 students to the control group. Each principal investigator provided information about the course in a 30-minute session with one of the groups. Both sessions opened with the same general description of the course and showed research (by other investigators) that described the widespread use of games, simulations, and workshops in business schools and in other organizations to train students and managers to lead. Both presentations stressed how the business game simulates the real world. In the experimental session the investigator presented a PowerPoint presentation describing how the course could be useful for the students. They were told that the game was used in top business schools around the world. They were shown (contrived) words of praise of students who had played the same game at leading universities. They included words and phrases such as "practical," "action-oriented," "realistic skill-practice," "acquired useful skills," and "lessons for life." Two concluding 
quotes were, "The business game probably contributed more to my management career than anything else at the university" and "The business game was the perfect end to a great MBA program."

Simultaneously, the other principal investigator conducted a PowerPoint session on stress and coping in the business game and in life with the control group. Role stress was described as involving conflict, ambiguity, and overload. The business game was portrayed in the words of previous students as very interesting but loaded with tasks and assignments that require investing many hours. The students were told that planning and prioritizing their work and social support from family and friends may help reduce stress. Types and sources of social support were defined and discussed. Students in both groups completed measures of business-game efficacy as a manipulation check and measures of the other variables hypothesized to play a role and affect performance.

\section{Treatment Boosters}

To refresh and strengthen the experimental treatment, we sent the participants two electronic mail messages titled, "Follow-up Questionnaire." These messages repeated very briefly the information about the course that had been presented in the experimental and control treatments. The experimental version was, "We know that many graduates regard the game as highly useful as a tool in promoting their management career several years after having played it. Please state very briefly two or three aspects of the game you identify as particularly likely to aid you in your career in the future:" This was intended to get them thinking again about how useful the game/course is. The control version was, "We know many participants experience stress playing the game. Please state very briefly two or three aspects of the game that you have been experiencing as particularly stressful." Both versions then asked the respondents to answer short questions about how they were experiencing the game.

\section{Measures}

Means Efficacy. We devised 14 5-point items especially for this experiment. Respondents read this introduction: "Think of the business game as a means for developing your management career. Indicate the extent to which you believe each of the following statements is true: The business game can:" which was followed by 14 ways in which the game might be a useful means for the students (e.g., "...contribute useful management tools"; "...help me understand the culture of business"; "...promote my career in management." Coefficients $\alpha$ were .94 and .96 on the first and second occasions, respectively.

GSE. The NGSE (Chen et al., 2001) measured GSE; in the present experiment $\alpha=.85$ and .95 on the first and second occasions, respectively. Because they worked in teams and the main grade was based on the team performance, we assessed team efficacy using 12 items developed by Chen, Webber, Bliese, Mathieu, Payne, Born, and Zaccaro (2002) to measure collective efficacy. We used it to gauge individual team members' belief in the ability of their team to perform effectively. Respondents indicated on a 5-point scale: "How confident are you in your team's ability to do the following actions:" Sample items are "Work together as one unit"; "Cooperate well with each other"; "Perform better than most other teams." Coefficients $\alpha$ were .88 and .94 for the first and second occasions, respectively.

Learning Motivation. Vallerand, Pelletier, Blais, Briere, Senecal, and Vallieres (1992) developed and validated the 28-item Academic Motivation Scale $(\alpha=.81$; test-retest reliability coefficient $=.79)$ and suggested using it for educational research on motivation. We adopted and adapted four of their items ("I prefer challenging and difficult courses that enable me to learn a lot"; "I enjoy learning for its own sake"; "I like studies that make me think"; "I am willing to enroll in a difficult program of study if I can learn a lot from it"; $\alpha=.88$ ).

To measure stress, we adapted Crum, Salovy, and Achor (2014)'s measure. It asks respondents on a 7point scale "How much stress are you experiencing in your life right now?" Crum et al. also asked, "How stressful do you perceive [a primary source of stress] to be?" We expanded Crum et al.'s primary source to the two leading sources of stress in participants' lives: "How much stress are you experiencing in your job?" and "How much stress are you experiencing in your studies?" For our three items coefficients $\alpha$ were .74 and .91 on the first and second occasions, respectively. 
Performance. Performance was gauged using final grades. These were comprised of team performance in the game generated by objective, quantitative performance indicators $(70 \%)$, a paper $(20 \%)$, and attendance $(10 \%)$.

\section{Results}

Table 3 displays the results. No variable changed significantly from pretest to posttest in either group, nor was the Treatment X Occasion interaction significant for any variable. The constancy of course efficacy means that our experimental treatment failed to influence the means efficacy of the experimental group. The unavoidable conclusion is, again, that this experiment did not test the means-efficacy hypothesis.

The hypothesized mediators and ancillary outcomes similarly remained unchanged despite the experimental treatment. Finally, the grades do not show any experimental-control difference. With this tiny number of test scores, the difference of less than two points on the 100-point grade scale hardly requires a statistical test.

TABLE 3

COMPARISON OF EXPERIMENTAL AND CONTROL GROUPS IN THE BUSINESS GAME, EXPERIMENT 2

\begin{tabular}{|c|c|c|c|c|c|c|c|}
\hline \multirow[b]{2}{*}{ Variable } & \multirow[b]{2}{*}{ Occasion } & \multicolumn{2}{|c|}{ Experimental } & \multicolumn{2}{|c|}{ Control } & \multirow[b]{2}{*}{$t$} & \multirow[b]{2}{*}{$F_{\text {int }}$} \\
\hline & & $M$ & $S D$ & $M$ & $S D$ & & \\
\hline \multirow{2}{*}{$\begin{array}{l}\text { Means } \\
\text { efficacy }\end{array}$} & 1 & 3.33 & 0.68 & 3.00 & 0.43 & 1.49 & \multirow{2}{*}{0.00} \\
\hline & 2 & 2.96 & 0.99 & 2.90 & 0.63 & 1.47 & \\
\hline \multirow{2}{*}{$\begin{array}{l}\text { General self- } \\
\text { efficacy }\end{array}$} & 1 & 4.20 & 0.38 & 4.26 & 0.43 & 0.45 & \multirow{2}{*}{0.03} \\
\hline & 2 & 3.91 & 1.04 & 4.12 & 0.69 & 0.50 & \\
\hline \multirow{2}{*}{$\begin{array}{l}\text { Team } \\
\text { efficacy }\end{array}$} & 1 & 4.25 & 0.84 & 4.14 & 0.42 & 0.46 & \multirow{2}{*}{1.43} \\
\hline & 2 & 3.75 & 1.06 & 4.16 & 0.62 & 0.33 & \\
\hline \multirow{2}{*}{$\begin{array}{l}\text { Learning } \\
\text { motivation }\end{array}$} & 1 & 3.61 & 0.86 & 3.47 & 0.92 & 0.50 & \multirow{2}{*}{0.33} \\
\hline & 2 & 3.72 & 1.17 & 3.56 & 0.38 & 0.98 & \\
\hline \multirow[t]{2}{*}{ Stress } & 1 & 4.31 & 0.89 & 4.35 & 0.74 & 0.14 & \multirow{2}{*}{0.96} \\
\hline & 2 & 4.45 & 1.65 & 5.04 & 1.11 & 0.86 & \\
\hline Grades $^{\mathrm{a}}$ & & 86.09 & 8.85 & 87.83 & 4.93 & 0.62 & \\
\hline
\end{tabular}

Note. Occasion $1-n=25$ experimental and 15 control.

Occasion $2-n=11$ experimental and 8 control.

${ }^{\mathrm{a}} n=22$ experimental and 12 control. 


\section{Discussion}

One possible reason why the experimental treatment did not work is, again, the control treatment. The control students gained important knowledge about stress, coping, and social support. Perhaps this built a kind of coping efficacy that was as effective a motivator as the means efficacy treatment. It may have been a mistake to convey this knowledge to the control group. If we created conditions under which both groups acquired something that aided them in their studies, with our own hand we undermined our attempt to test the hypothesis and to obtain confirmatory results. This is a likely explanation because the control treatment prepared the control students to cope more effectively with the demands of the game; this may be as helpful as strengthening course efficacy in the experimental group. Furthermore, although we had randomly assigned teams to experimental and control groups, we learned at the end of the game that some students "unofficially" had switched teams. This left us with very few teams that were identical in their makeup as originally assigned. We ended up with too few cases to analyze.

\section{(QUASI)EXPERIMENT: LAW COURSE}

One idea that arose to explain these lackluster results was the level of the students. In all the previous experiments, they were management graduate students. Perhaps the experimental treatment would work better among undergraduates. The next experiment involved undergraduate management students.

\section{Sample and Design}

We conducted this study among five sections of the required introductory business-law course for accounting students in a B.B.A. program. We assigned two sections to the experimental condition and three sections to the control condition. To control instructor effects, each of two lecturers taught an experimental section and a control section. The third control group had a different lecturer; however, the pretest means of this control group were very similar to those of the other two control groups. The sections met at different times during the week, providing experimental insulation. However, because whole sections were assigned and there were only five sections, there were insufficient degrees of freedom for analysis at the group level. Analyzing the data at the individual level rendered this a quasi-experiment because individual students were not assigned to sections at random. The experimental sections at Time 1 numbered 181 and the control sections numbered 211 individuals. Ninety-seven individuals in the experimental sections and 104 individuals in the control sections completed both pretest and posttest questionnaires.

\section{Experimental Treatment}

This time we tried a combination of a student model backed by academic authority. The Dean of Students collaborated. The model was a third-year student in the same B.B.A. program whom the dean knew well and who had taken the same course two years previously. We recruited him to play the confederate role for pay. The dean entered each section's first class session that semester to describe her role as Dean of Students. In the two experimental sections only, she was accompanied by the confederate. She told the students a) that by chance she "bumped into" the confederate in the hallway on her way to this class; b) that she told him she was on her way to a section of "Introduction to Business Law"; c) that he had remarked that that course was significant for him and that it had contributed much to his professional work; and d) that she asked him off-the-cuff to come along with her to tell that to the students and he agreed. In fact, this student - who actually had taken this course - had been well briefed in advance to fulfill the role of an advanced student who had taken that course and "just happened to be around" at that time.

The confederate's role had been rehearsed. He introduced himself and said he came along to share his experiences and learning in that course now, after two full years of study in the program. He emphasized how much the course helped him as a manager. He stressed its contribution to practice and to understanding management processes. He added how it helped him to cope with client relations and with legal issues. The dean then thanked and dismissed the confederate and continued describing her role as dean. She appeared in the three control sections unaccompanied. 
As a treatment booster, during the seventh week of the semester the dean returned to refresh the original experimental treatment in the experimental students' minds. She reintroduced herself and announced details of the upcoming exam schedule and sundry administrative issues and answered questions. In the experimental sections only she preceded these administrative comments with an opening in which she said she recalled dragging into this section a former student she had bumped into in the hall who praised the course and its contribution to his career.

\section{Measures}

Course efficacy, in the present context, is law-course efficacy. We tailored 14 items to measure lawcourse efficacy, that is, students' belief in the law course as a useful means for achieving success in management. Respondents read this introduction: "Studying law may contribute to success in management. Think of Introduction to Law as a means for developing your management career. Indicate the extent to which you believe each of the following statements is true. Introduction to Law can:" which was followed by 14 ways in which the course might be a useful means for the participants (e.g., "...contribute useful management tools"; "...help me understand the culture of business"; "...help me to understand the legal aspects of managing people"; $\alpha=.94$.

GSE (general self-efficacy) was measured using the NGSE (New General Self-efficacy) Scale (Chen et al., 2001; present $\alpha=.90$ ).

Motivation to learn was measured with seven items devised for this experiment. Respondents indicated the extent to which they agreed with statements such as, "I was waiting impatiently for Introduction to Law"; "The contents of Introduction to Law arouse my curiosity"; "It is important to me to internalize the contents of Introduction to Law" $(\alpha=.89)$.

Specific self-efficacy was measured using 12 items devised to tap students' beliefs regarding their abilities to cope with a demanding course. This set of questions was preceded by: "To succeed in one's studies one must cope with many and varied tasks. Different students believe different things about their abilities to cope with courses. The following statements regard your beliefs about your abilities to cope with courses. Please indicate the extent to which you believe you are able to cope with course demands." Items included, "To turn in assignments on time"; "To concentrate on your studies"; "To remember the material for the exam"; $\alpha=.88$.

Vigor is a component of work engagement. We measured vigor using six 6-point items from the engagement scale (Schaufeli \& Bakker, 2010). Sample items are: "I am bursting with energy when I study"; "I get excited about my studies"; "I can study for protracted periods of time" $(\alpha=.87)$.

\section{Results}

Row 1 in Table 4 shows that at pretest, the experimental participants reported greater course efficacy than did the control participants $(4.19-4.05=0.14)$, but this difference was not statistically significant, nor was Cohen's $d$ substantial. Then, comparing Rows 1 and 2 reveals that from pretest to posttest course efficacy declined in both groups. The decline was smaller in the experimental group $(4.19-3.99=0.20)$ than in the control group $(4.05-3.70=0.35)$ though the difference in the degree of decline was not statistically significant $\left(0.20\right.$ vs. $0.35 ; F_{\text {int }}=2.08$, n.s. $)$. But the mean difference between the groups at posttest grew larger $(3.99-3.70=0.29)$. We had to conclude that these results are teasingly nonsignificant and nonconfirmatory. Thus, the manipulation check failed.

Rows 3 and 4 show that GSE, a stable trait, remained unchanged as expected. Specific self-efficacy (Rows 5 and 6) came close to confirming the mediating hypothesis; it declined in both groups, but more in the control group than in the experimental group $(4.16-3.85>4.31-4.15)$. This difference in pretestposttest change was of borderline significance $\left(F_{\text {int }}=3.11, p=.079\right)$. The one potential mediator that did confirm the mediation hypothesis was vigor. The last two rows in Table 4 show that vigor declined in both groups but significantly more in the control group $(4.78-3.90=0.88)$ than in the experimental group $(4.62$ $-4.19=0.43$; for the Group X Occasion interaction, $\left.F_{\text {int }}=8.82, p=.003\right)$. Thus, vigor and specific selfefficacy decreased in both groups but more in the control group. 
Performance in the course did not differ, as manifested in the students' course grades $(M=85$ in both experimental and control groups). Thus, the hypothesis that raising course efficacy improves performance was neither tested nor confirmed.

The significant Group X Occasion interaction for vigor and the borderline Group X Occasion interaction for specific self-efficacy might indicate that, although the manipulation check was not significant, something in the course caused vigor and specific self-efficacy to decline in both groups. It seems students started the course with reasonably high vigor and specific self-efficacy but something reduced them. Perhaps course overload or disappointment with the course reduced vigor and specific selfefficacy. While the experimental treatment did not raise course efficacy, it may have raised self-esteem or resilience in the experimental group which caused this effect. Further experimentation is needed to test whether these findings replicate.

\section{TABLE 4 \\ COMPARISON OF EXPERIMENTAL AND CONTROL GROUPS, LAW COURSE QUASI- EXPERIMENT 3}

\begin{tabular}{|c|c|c|c|c|c|c|}
\hline \multirow[b]{2}{*}{ Variable } & \multicolumn{2}{|c|}{ Experimental } & \multicolumn{2}{|c|}{ Control } & \multirow[b]{2}{*}{$F_{\text {int }}$} & \multirow[b]{2}{*}{ Cohen's d } \\
\hline & $M$ & $S D$ & $M$ & $S D$ & & \\
\hline \multicolumn{7}{|c|}{ Course efficacy } \\
\hline $\mathrm{T} 1$ & 4.19 & 0.56 & 4.05 & 0.58 & \multirow{2}{*}{2.08} & 0.24 \\
\hline $\mathrm{T} 2$ & 3.99 & 0.70 & 3.70 & 0.85 & & 0.37 \\
\hline \multicolumn{7}{|c|}{ General self-efficacy } \\
\hline $\mathrm{T} 1$ & 4.27 & 0.52 & 4.29 & 0.56 & \multirow{2}{*}{0.023} & 0.03 \\
\hline $\mathrm{T} 2$ & 4.31 & 0.51 & 4.28 & 0.61 & & 0.05 \\
\hline \multicolumn{7}{|c|}{ Specific self-efficacy } \\
\hline $\mathrm{T} 1$ & 4.31 & 0.63 & 4.16 & 0.66 & \multirow[b]{2}{*}{$3.11^{\mathrm{a}}$} & 0.23 \\
\hline $\mathrm{T} 2$ & 4.15 & 0.53 & 3.85 & 0.68 & & 0.49 \\
\hline \multicolumn{7}{|l|}{ Vigor } \\
\hline $\mathrm{T} 1$ & 4.62 & 0.84 & 4.78 & 0.77 & \multirow{2}{*}{$8.82 * *$} & 0.20 \\
\hline $\mathrm{T} 2$ & 4.19 & 0.96 & 3.90 & 0.99 & & 0.30 \\
\hline
\end{tabular}

\section{GENERAL DISCUSSION}

\section{Summary of Findings}

In the second pilot study the manipulation check had validated the treatment and regression analysis had revealed correlational support for the course-efficacy hypothesis. However, the manipulation check failed in all three follow-on experiments. This precluded experimental testing of our main hypothesis in these experiments. Though not our major aim, Experiment 1 yielded further support for the plasticity hypothesis. Experiment 2 yielded no results worth mentioning. Despite the promise of the business game as a learning and performance arena amenable to testing the course-efficacy hypothesis, we did not foresee the unauthorized switching of individuals from one team to another. This left us with pitifully few degrees 
of freedom for hypothesis testing. In Experiment 3 no result confirmed the hypothesis. All in all, there is little in the findings of these three experiments that supports the means-efficacy hypothesis.

\section{Appraisal of the Present Findings}

These experiments had two main objectives: (a) to enhance our knowledge of means efficacy and the ways to increase it; (b) to test the effects of course efficacy on performance. The present experiments focused, for the first time, on boosting course efficacy, which is students' belief in the usefulness of a university course to help them in some important future performance. In a pilot study we showed that a course can be regarded as a means. This bolsters the fact that means efficacy is beginning to earn a respectable place beside self-efficacy as a fountainhead of work motivation and performance research. In practical terms, this may be useful in training and in consulting intended to help managers enhance employee efficacy beliefs, motivation, and performance. Furthermore, means efficacy has crucial implications for how managers can lead more effectively (Hannah, Avolio, Walumbwa, \& Chan, 2012; Walumbwa et al., 2008). It is not enough to provide employees with effective tools or training; gaining the full practical benefit of investing in such costly means requires leading people to believe that these means can work well for them.

However, the cumulative findings from two pilots and three experiments are meagre and hardly confirmatory. Varying type of course, level of students, demographic characteristics of experimenter, and type of booster did not improve the effects of the experimental treatment. This series of experiments is rich in replications, so often lacking in research (Furchtgott, 1984). Unfortunately, the null hypothesis dominated these replications.

\section{Why Didn't We Get More Confirmatory Results?}

The most obvious answer to this question that cannot be ignored is that the null hypothesis is correct; strengthening means efficacy does not enhance performance. However, in face of the accumulated confirmatory field-experimental evidence that strengthening means efficacy does indeed enhance performance, this explanation is not tenable. The explanation likely lies in the nature of the particular means we chose to study.

\section{Is a University Course a Means?}

A course is not a "means" in the same sense as a hammer, a forklift, or a computer. Perhaps our portrayal of the course as a means for developing a successful management career is unconvincing to students. This explanation is supported by our varying the experimental treatment to make it credible: using students as models, using a manager, using a dean, and conducting the experimental treatment ourselves. Despite our careful planning and intense efforts, the student participants simply didn't "buy" it. Perhaps in this stage of their lives, what students want most is to get the course out of their way and get their degree and not how this particular course may be instrumental to their career success. Failing to raise experimental participants' course efficacy repeatedly precluded testing the hypothesis. Thus, it is premature to conclude that boosting course efficacy does not enhance performance, and certainly no basis for rejecting the general hypothesis that boosting means efficacy enhances performance.

The present meagre results diverge from those of Rotstein and Erez (2010), who found a strong relationship between means efficacy and post-training employment status, especially among trainees with high core self-evaluations. They found nonexperimentally what we did not produce experimentally. Perhaps the explanation lies in differences in population and setting. Rotstein and Erez' sample of new immigrants, mostly older and nonacademic, may view their occupational retraining very differently from the way university students view one particular course that is part of a whole program of studies. Their new immigrants had much more riding on their reemployment training than university students have riding a one course. Perhaps boosting the means efficacy of a course would succeed more among individuals enrolled in any stand-alone, nonacademic training course than among university students with regard to one course selected from an entire academic degree program. We have lumped together training as done in 
organizations with university courses as learning situations in which the course-efficacy hypothesis can be tested. We overlooked crucial differences between these diverse settings and populations.

An anomaly in Rotstein and Erez' (2010) results is that among those high in CSE the relationship between course efficacy and reemployment was stronger than among those low in CSE. This contradicts the plasticity hypothesis, according to which one would expect the relationship to be stronger among those low in CSE. We offer no explanation of this contradiction.

\section{Experienced Managers as Participants}

Another reason for our spotty success in raising course efficacy may be the fact that many of our participants were experienced, albeit low-level, practicing managers. Experience gives them a sound basis for judging the importance of a course or its potential contribution to their future success. It was natural for us to study management students. However, being BBA or MBA students, their experience in the world of management may have reduced the likelihood of our being able to "sell" them on organizational behavior courses. It is common knowledge that most business students highly value courses in finance and marketing and view $\mathrm{OB}$ as somewhat less important. Replications should be attempted in courses on topics that are completely new to the participants or perhaps to whole-year programs to test program efficacy.

\section{Suggestions for Future Research}

Perhaps future experimenters should abandon trying to cast university courses as means. Perhaps the course-efficacy experimental treatment fails because students are accustomed to hearing instructors praise whatever course they are teaching at the beginning of virtually every course. Having heard it so many times renders our experimental treatment "More of the same" or "We've heard that before" and leaves students unimpressed. Furthermore, perhaps what they hear about courses from their fellow students who have taken these courses before outweighs anything we might say in the experimental treatment.

If replicators persist in testing means efficacy in university courses, they might broaden the types of outcomes "promised" in the experimental treatment to include increased chances of landing a good job, getting into a leading university, or gaining acceptance to a higher degree program. Replicators might add more treatment boosters. We did what seemed feasible under the circumstances of the courses we studied. Future experimenters may devise more and better ways to conduct boosters throughout the duration of the course or training.

Means-efficacy experimenters have an enormous variety of other means to investigate. Experimenters could, for example, study use of seat belts, crash helmets, or face masks. People often say, "That won't prevent an accident," or "I won't get into any accident," or "I won't contract Covid-19." This extends to industrial safety programs at large; getting employees to adhere to safety regulations is hard due to the tendency of trainees to doubt their effectiveness (Hofmann, Burke, \& Zohar, 2017; Zohar, 1980).

Another means that could be studied is medical treatments. Patients are notorious for not adhering to prescribed medical regimens and many ordinary citizens do not wear face masks during the Corona pandemic. Worse, millions worldwide refuse vaccination. According to the WHO, $30 \%$ to $50 \%$ of patients with chronic illnesses fail to take their medication as prescribed (DiMatteo, 2004; Sabaté, 2003). Much of this may derive from patients' disbelief, or shaky belief, in the prescribed medications or in their belief in the efficacy of wearing face masks or of the immunizing vaccine. Boosting their means efficacy for the prescribed treatments and masks may increase adherence. The remedy-efficacy treatment would involve communicating persuasive messages to patients about their prescribed remedies and information to the public regarding the efficacy of face masks and vaccinations.

\section{Epilogue}

The field experiment is a means. It is a means for conducting rigorous, causally unambiguous research in social science to unlock nature's secrets (Eden, 2017). After two pilots and three experimental attempts to test the course-efficacy hypothesis that all in all reaped disappointing results, one may be tempted to blame the means. Three experiments and two pilot studies of varying completeness yielded less persuasive evidence in support of the hypothesis than did Rotstein and Erez' (2010) single nonexperimental field study. 
Nevertheless, we do not despair of the method. The problem lies with the hypothesis, the experimental treatments, the settings, or the type of courses we studied. For us, the field experiment remains the gold standard and it still has supreme means efficacy for causally-unambiguous organizational psychology research.

\section{ACKNOWLEDGEMENT}

We gratefully acknowledge the support of grant number Grant No. 1465/15 from the Israel Science Foundation to Dov Eden and Mina Westman.

\section{REFERENCES}

Agars, M.D. (2010, April). Perceptions of resources matter: Means efficacy and career choices. Paper presented at the 25th Annual Conference of the Society for Industrial and Organizational Psychology, Atlanta.

Bandura, A. (1997). Self-efficacy: The exercise of control. New York: Freeman.

Ben Zvi, T. (2007). Using business games in teaching DSS. Journal of Informational System Education, 18, 113-124. Retrieved from https://ssrn.com/abstract=2150652

Brockner, J. (1985). The relation of trait self-esteem and positive inequity to productivity. Journal of Personality, 53, 517-529. https://psycnet.apa.org/doi/10.1111/j.1467-6494.1985.tb00380.x

Brockner, J. (1988). Self-esteem at work: Research, theory, and practice. Lexington, MA: Lexington Books.

Chen, G., Gully, S. M. \& Eden, D. (2001). Validation of a new general self-efficacy scale. Organizational Research Methods, 4, 62-83. https://doi.org/10.1177\%2F109442810141004

Chen, G., Webber, S.S., Bliese, P.D., Mathieu, J.E., Payne, S.C., Born, D.H., \& Zaccaro, S.J. (2002). Simultaneous examination of the antecedents and consequences of efficacy beliefs at multiple levels of analysis. Human Performance, 15, 381-409. https://doi.org/10.1207/S15327043HUP1504_05

Chen, S., Westman, M., \& Eden D. (2009). Impact of enhanced resources on anticipatory stress and adjustment to new information technology: A field-experimental test of Conservation of Resources Theory. Journal of Occupational Health Psychology, 14, 219-348. https://doi.org/10.1037/a0015282

Chen, S., Westman, M., Eden, D., \& Toker, S. (2011, December). Raising means efficacy to improve satisfaction and performance. Presented at the First Israel Organizational Behavior Conference, Tel Aviv University, Tel Aviv, Israel.

Crum, A. J., Salovy, P., \& Achor, S. (2013). Rethinking stress: The role of mindset in determining the stress response. Journal of Personality and Social Psychology, 104, 716-733. https://psycnet.apa.org/doi/10.1037/a0031201

Cruz-Cunha, M.M. (Ed). (2012). Handbook of research on serious games as educational, business and research tools (Vols. I \& II, pp. 859-872). Hershey, PA: Information Science Reference/IGI Global.

DiMatteo, M. R. (2004). Variations in patients' adherence to medical recommendations: A quantitative review of 50 years of research. Medical Care, 42(3), 200-209.

Eden, D. (2001). Means efficacy: External sources of general and specific subjective efficacy. In M. Erez, U. Kleinbeck, \& H. Thierry (Eds.), Work motivation in the context of a globalizing economy (pp. 73-85). Mahwah, NJ: Lawrence Erlbaum.

Eden, D. (2013). Means efficacy: The flowering of a novel construct. In B.J. Avolio \& F.J. Yammarino (Eds.), Transformational and charismatic leadership: The road ahead (2nd ed.-10th Anniversary Edition) (pp. 359-363). Bingley, UK: Emerald/JAI.

Eden, D. (2017). Field experiments in organizations. Annual Review of Organizational Psychology and Organizational Behavior, 4, 91-122. https://doi.org/10.1146/annurev-orgpsych-041015-062400 
Eden, D., \& Aviram, A. (1993). Self-efficacy training to speed reemployment: Helping people to help themselves. Journal of Applied Psychology, 78, 352-360. https://psycnet.apa.org/doi/10.1037/0021-9010.78.3.352

Eden, D., Ganzach, Y., Flumin-Granat, R., \& Zigman, T. (2010). Augmenting means efficacy to boost performance: Two field experiments. Journal of Management, 36, 687-713. https://psycnet.apa.org/doi/10.1177/0149206308321553

Eden, D., \& Sulimani, R. (2002). Pygmalion training made effective: Greater mastery through augmentation of self-efficacy and means efficacy. In B.J. Avolio \& F.J. Yammarino (Eds.), Transformational and charismatic leadership: The road ahead. Oxford, UK: Elsevier.

Eden, D., \& Zuk, Y. (1995). Seasickness as a self-fulfilling prophecy: Raising self-efficacy to boost performance at sea. Journal of Applied Psychology, 80, 628-635. https://psycnet.apa.org/doi/10.1037/0021-9010.80.5.628

Festinger, L. (1954). A theory of social comparison processes. Human Relations, 7, 117-140. https://doi.org/10.1177\%2F001872675400700202

Furchtgott, E. (1984). Replicate, again and again. American Psychologist, 39, 1315-1316. https://psycnet.apa.org/doi/10.1037/0003-066X.39.11.1315.b

Geithner, S., \& Menzel, D. (2016). Effectiveness of learning through experience and reflection in a project management simulation. Simulation \& Gaming, 47, 228-256. https://doi.org/10.1177\%2F1046878115624312

Gist, M.E., \& Mitchell, T.R. (1992). Self-efficacy: A theoretical analysis of its determinants and malleability. Academy of Management Review, 17, 183-211. https://psycnet.apa.org/doi/10.2307/258770

Gold, S.C., \& Wolfe, J. (2012). The validity and effectiveness of a business game beta test. Simulation \& Gaming, 43, 481-505. https://doi.org/10.1177\%2F1046878111431868

Hannah, S.T., Avolio, B.J., Walumbwa, F.O., \& Chan, A. (2012). Leader Self and Means Efficacy: A multi-component approach. Organizational Behavior and Human Decision Processes, 118(2), 143-161. http://dx.doi.org/10.1016\%2Fj.obhdp.2012.03.007

Hendrick, C. (1990). Replications, strict replications, and conceptual replications: Are they important? Journal of Social Behavior and Personality, 5(4), 41-50.

Hofmann, D.A., Burke, M.J., \& Zohar, D. (2017). 100 years of occupational safety research: From basic protections and work analysis to a multilevel view of workplace safety and risk. Journal of Applied Psychology, 102(3), 375-388. https://psycnet.apa.org/doi/10.1037/ap10000114

Jones, M.M., Agars, M.D., \& Kottke, J.L. (2010, April). Means efficacy and self-efficacy: Testing their unique effects on performance. Presented at the 25th Annual Conference of the Society for Industrial and Organizational Psychology, Atlanta.

Levy, S., Freitas, A., \& Salovey, P. (2002). Construing actions abstractly and blurring social distinctions: Implications for perceiving homogeneity among, but also empathizing with helping others. Journal of Personality and Social Psychology, 83, 1224-1238. https://psycnet.apa.org/doi/10.1037/0022-3514.83.5.1224

Lykken, D.T. (1968). Statistical significance in psychological research. Psychological Bulletin, 70, 151159. https://psycnet.apa.org/doi/10.1037/h0026141

Maddux, J.E., \& Kleiman, E.M. (2018). Self-efficacy. In G. Oettingen, A.T. Sevincer, \& P. Gollwitzer (Eds.), The psychology of thinking about the future (pp. 174-198). New York, NY: Guilford Press.

Rice, J.A., Kottke, J.L., \& Agars, M. (2010, April). Quality and quantity means: Confidence boosts regardless of initial self-efficacy. Presented at the 25th Annual Conference of the Society for Industrial and Organizational Psychology, Atlanta.

Rosenthal, R. (1990). Replication in behavioral research. Journal of Social Behavior and Personality, $5(4), 1-30$. 
Rotstein, A., \& Erez, M. (2010). Effects of means efficacy \& core self-evaluations on employment status. Paper presented at the 25th Annual Conference of the Society for Industrial and Organizational Psychology, Atlanta.

Sabaté, E. (2003). Adherence to long-term therapies: Evidence for action. Geneva: World Health Organization. Retrieved from https://apps.who.int/iris/handle/10665/42682

Sade, N. (2013). Boosting course efficacy and its impact on course performances (master's thesis). The Leon Recanati Graduate School of Business Administration, Tel Aviv University, Tel Aviv, Israel.

Schaufeli, W.B., \& Bakker, A.B. (2010). Defining and measuring work engagement: Bringing clarity to the concept. In A.B. Bakker \& M.P. Leiter (Eds.), Work engagement: A handbook of essential theory and research (pp .10-24). New York: Psychology Press.

Shelton, S.H. (1990). Developing the construct of general self-efficacy. Psychological Reports, 66(3, Pt 1), 987-994.

Stajkovic, A.D., \& Luthans, F. (1998). Self-efficacy and work-related performance: A meta-analysis. Psychological Bulletin, 124, 240-261. http://dx.doi.org/10.1037/0033-2909.124.2.240

Stirin, K., Ganzach, Y., Pazy, A., \& Eden, D. (2011). The effect of perceived advantage and disadvantage on performance: The role of external efficacy. Applied Psychology: An International Review, 61, 81-96. https://doi.org/10.1111/j.1464-0597.2011.00457.x

Tesser, A., Millar, M., \& Moore, J. (1988). Some affective consequences of social comparison and reflection processes: The pain and pleasure of being close. Journal of Personality and Social Psychology, 54, 49-61. https://psycnet.apa.org/doi/10.1037/0022-3514.54.1.49

Vallerand, R.J., Pelletier, L.G., Blais, M.R., Briere, N.M., Senecal, C., \& Vallieres, E.F. (1992). The Academic Motivation Scale: A measure of intrinsic, extrinsic, and amotivation in education. Educational and Psychological Measurement, 52, 1003-1017. https://doi.org/10.1177\%2F0013164492052004025

Vancouver, J.B., \& Purl, J.D. (2017). A computational model of self-efficacy's various effects on performance: Moving the debate forward. Journal of Applied Psychology, 102, 599-616. https://psycnet.apa.org/doi/10.1037/ap10000177

Walumbwa, F.O., Avolio, B.J., \& Zhu, W. (2008). How transformational leadership weaves its influence on individual job performance: The role of identification and efficacy beliefs. Personnel Psychology, 61, 793-825. https://psycnet.apa.org/doi/10.1111/j.1744-6570.2008.00131.x

Wolfe, J. (2016). Assuring business school learning with games. Simulation \& Gaming, 47, $206-227$. https://doi.org/10.1177\%2F1046878116632872

Yaakobi, E., \& Weisberg, J. (2018). Individual, group and organizational efficacies in predicting performance. Personnel Review, 47, 535-554. https://doi.org/10.1108/PR-08-2016-0212

Yokoyama, S. (2019). Academic self-efficacy and academic performance in online learning: A mini review. Frontiers in Psychology, 9, 2794. https://doi.org/10.3389/fpsyg.2018.02794

Zhou, L., Wang, M., Chang, C.H., Liu, S., Zhan, Y., \& Shi, J. (2017). Commuting stress process and self regulation at work: Moderating roles of daily task significance, family interference with work, and commuting means efficacy. Personnel Psychology, 70, 891-922.

https://doi.org/10.1111/peps.12219

Zohar, D. (1980). Safety climate in industrial organizations: Theoretical and applied implications. Journal of Applied Psychology, 65, 96-102. https://doi.org/10.1037/0021-9010.65.1.96 